Check for updates

The BMJ

Cite this as: $B M J 2020 ; 371: m 4564$ http://dx.doi.org/10.1136/bmj.m4564 Published: 23 November 2020

\title{
Covid-19: Oxford vaccine is up to $90 \%$ effective, interim analysis indicates
}

\section{Elisabeth Mahase}

The covid-19 vaccine candidate developed by the University of Oxford is 90\% effective when a person is initially given a half dose followed by a full dose, interim phase III trial results show.

The analysis included 131 covid-19 cases and showed the vaccine was $62 \%$ effective when given as two standard doses (8895 participants) one month apart, but $90 \%$ effective when a half dose followed by a standard dose regime (2741) was used. No hospitalised or severe cases were found in anyone who received the vaccine.

The findings have not yet been peer reviewed or published, and were press released on 23 November. The vaccine team said they hoped to submit for publication within 24 hours.

The vaccine's manufacturer, AstraZeneca, said that four million full doses will be available in the UK by the end of 2020, which could be used to vaccine eight million people if the half dose regime is followed. Some 40 million full doses (80 million half doses) should be available in the UK by the end of the first quarter of 2021.

Globally, AstraZeneca said that more than 300 million full doses will be available by the end of the first quarter of 2021. At peak manufacturing capacity, 100 to 200 million doses of the vaccine-which is stored at fridge temperature $\left(2\right.$ to $\left.8^{\circ} \mathrm{C}\right)-\mathrm{can}$ be produced in a month.

The team is already engaging with regulators around the world. In some countries, including the UK, they have already started rolling submissions, providing data for review as they get it. The submissions to regulators include safety information from over 24 ooo people from trials in Brazil, South Africa, and the UK who have been followed since April.

Sarah Gilbert, professor of vaccinology at the University of Oxford, who is leading the vaccine team, told a Science Media Centre press briefing, "It looks like this vaccine is working against severe disease because we do not have any hospitalisations or severe cases in any of the groups that were vaccinated. It's working against mild disease and there appears to be an impact on asymptomatic disease, too. That should make a big impact on transmission."

On why an initial half dose seems to produce better results, Gilbert suggested it may be because it "better mimics" a real infection. "It could be that giving a small amount of the vaccine to start with and following up with a big amount is a better way of kicking the immune response into action.”

Charlie Weller, head of vaccines at Wellcome, said, "These results suggest it's highly effective in protecting against serious illness and may reduce transmission. As with all interim results we've seen, it is critically important that the trial is completed and regulators can independently and rigorously assess the data."

The UK government said that, subject to approval and authorisation of the full data by the UK's Medicines and Healthcare Products Regulatory Agency, the NHS would begin to roll out the vaccine. "We have already secured early access to 100 million doses of their vaccine for use across the UK if approved-on top of 255 million doses from other vaccine developers," a government spokesperson said.

Throughout the development process the Oxford team has stressed that they want their vaccine to be accessible around the world and not just high income countries. As such, large scale manufacturing has been set up in over 10 countries and the team expects the vaccine to be available at a low price per dose. ${ }^{1}$

Mahase E. Covid-19: Pfizer and BioNTech submit vaccine for US authorisation. BMJ2020;371:m4552. doi: 10.1136/bmj.m4552 pmid: 33219049

This article is made freely available for use in accordance with BMJ's website terms and conditions for the duration of the covid-19 pandemic or until otherwise determined by BMJ. You may use, download and print the article for any lawful, non-commercial purpose (including text and data mining) provided that all copyright notices and trade marks are retained. 